\title{
DESCRIÇÃO DE Brontostoma doughertyae SP. NOV. E ESTUDO MORFOLÓGICO COMPARATIVO COM B. rubrum (AMYOT \& SERVILLE, 1843) (HEMIPTERA: HETEROPTERA: REDUVIIDAE: ECTRICHODIINAE)
}

\author{
Hélcio R. Gil-Santana ${ }^{(1)}$, Catarina M. Lopes(2), \\ Oton Meira Marques ${ }^{(3)} \&$ José Jurberg $^{(1)}$
}

\section{Abstract}

Description of Brontostoma doughertyae n. sp. and a comparative morphological study with B. rubrum (Amyot \& Serville, 1843) (Hemiptera: Heteroptera: Reduviidae: Ectrichodiinae) - Brontostoma doughertyae $\mathrm{n}$. sp. (Hemiptera-Heteroptera: Reduviidae: Ectrichodiinae), from Espírito Santo and Bahia States, Brazil is described based on male specimens. A comparative analysis between the phallic structures of Brontostoma rubrum (Amyot \& Serville, 1843) and B. doughertyae sp. nov. is presented. Three structures are important to distinguish them: the gonoporal process (PrG); support of the phallosoma (SPh) and the phallosoma (Ph). A key for the brazilian species of Brontostoma is presented.

Key words: Comparative morphology, phallic structures, species list, synonyms, Brontostoma

(1) Laboratório Nacional e Internacional de Referência em Taxonomia de Triatomíneos;

(2) Laboratório Transmissores de Leishmaniose; Departamento de Entomologia, Instituto Oswaldo Cruz, Av. Brasil 4365, Manguinhos, CEP: 21045-900 Rio de Janeiro, Brasil, Email: helciogil@uol.com.br; (3)Departamento de Fitotecnia, Escola de Agronomia, Universidade Federal da Bahia. CEP: 44380-000 Cruz das Almas, Bahia, Brasil.

Com auxílio do CNPq; Convênio Serviço Vigilância Sanitária (SVS) / FIOCRUZ

Endereço atual do autor de correspondência: Lab. de Díptera. Departamento de Entomologia, Instituto Oswaldo Cruz.

Recebido em: 15/06/2004.

Aceito em: 27/03/2005. 


\section{Resumo}

Brontostoma doughertyae sp. nov. (Hemiptera-Heteroptera: Reduviidae: Ectrichodiinae), proveniente dos Estados do Espírito Santo e Bahia, Brasil, é descrita com base em exemplares machos. Apresenta-se uma análise comparativa entre as estruturas fálicas de Brontostoma rubrum (Amyot \& Serville, 1843) e B. doughertyae sp. nov.. Observou-se que três estruturas se destacam como diagnósticos: o processo do gonoporo (PrG); o suporte do falosoma (SPh) e o falosoma (Ph). Uma chave para as espécies brasileiras de Brontostoma é apresentada.

Palavras-chave: Morfologia comparada, estruturas fálicas, lista das espécies, sinonímia, Brontostoma

\section{Introdução}

Encontrou-se uma nova espécie entre os exemplares de Ectrichodiinae procedentes de duas Reservas Florestais existentes no Estado do Espírito Santo: 1 - Reserva Florestal da Companhia Vale do Rio

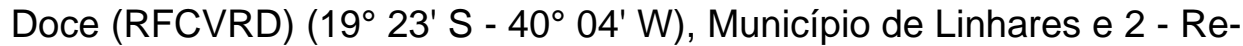
serva Biológica de Sooretama (antigo "Parque Sooretama") (190 $03^{\prime} \mathrm{S}$ $39^{\circ} 52^{\prime} \mathrm{W}$ ), Município de Sooretama e do Município de Barro Preto (anteri-

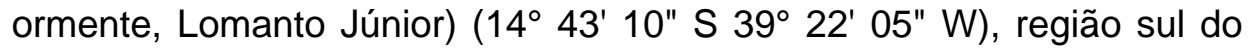
Estado da Bahia, Brasil (Fig. 1).

A fauna da região de Linhares e Sooretama tem semelhanças com a fauna Amazônica e possui um elevado número de espécies endêmicas (IBAMA, 2003).

A subfamília Ectrichodiinae é representada por 17 gêneros e 111 espécies nas Américas (Carpintero \& Maldonado Capriles, 1996). Dougherty (1995), na sua revisão dos Ectrichodiinae do Novo Mundo, indicou 19 gêneros válidos.

Embora discordantes quanto ao número de gêneros, ambos consideraram válido Brontostoma, não diferindo sensivelmente na sua delimitação morfológica e taxonômica. Dougherty (1995) sintetizou os caracteres atribuídos ao mesmo, os quais foram tratados com maior extensão por Carpintero \& Maldonado-Capriles (1996). 


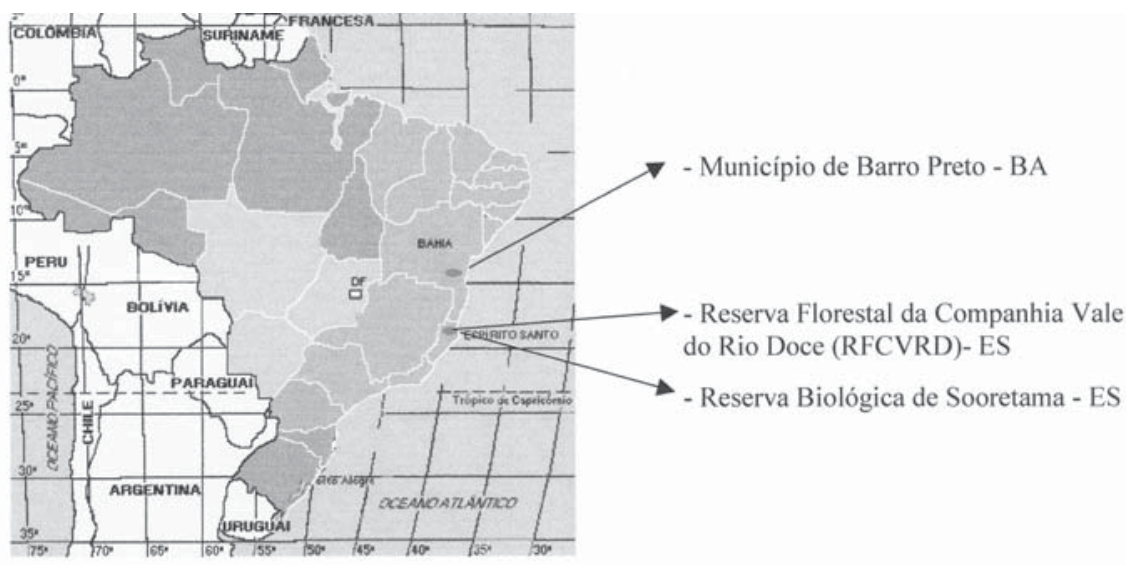

Figura 1: Mapa mostrando a localização da Reserva da CVRD, Município de Linhares, da Reserva Biológica de Sooretama, Município de Sooretama, Estado do Espírito Santo e do Município de Barro Preto, Estado da Bahia, Brasil.

As espécies de Brontostoma, de hábitos já observados, alimentamse em miriápodes e isópodos. A sua picada é muito dolorosa e é usualmente seguida por inflamação e paresia (Carpintero \& Maldonado Capriles, 1996). Por outro lado, uma espécie vetora do T. cruzi foi encontrada como presa de Brontostoma (Coscarón et al., 1999): Triatoma infestans (Klug, 1834) predado por Brontostoma discus (Burmeister, 1835) e B. fraternum (Stål, 1859).

A despeito do mimetismo aposemático ser um fenômeno amplamente encontrado entre os insetos (Tyler et al., 1994), o mesmo tem sido pouco estudado em Reduviidae (Gil-Santana et al., 2003). Dougherty (1995) relatou a ocorrência de coloração muito similar entre uma espécie não descrita de Brontostoma e um representante simpátrico de Hammacerinae.

As espécies descritas anteriormente à criação do gênero Brontostoma e nele incluídas atualmente, são: B. discus (Burmeister, 1835); B. haematodes (Blanchard, 1846) e B. rubrum (Amyot \& Serville, 1843) (Gil-Santana et al., 2004).

Ressalte-se que B. rubrum, quando descrito por Amyot \& Serville (1843), como Ectrichodia rubra, foi citada como procedente de Java. Embora Wygodzinsky (1949) tenha registrado a inexatidão dessa observação, referindo ser espécie comum no Brasil, Stål (1872), já registrava a 
espécie somente para "Brasilia [=Brasil], Bahia", baseando-se em exemplares do Museu de Estocolmo.

Oito espécies incluídas em Brontostoma foram descritas por Stål (1859, 1860 e 1872): B. alboannulatum (Stål, 1860), B. basalis (Stål, 1859), B. circumductum (Stål, 1859), B. fraternum (Stål, 1859), B. notatum (Stål, 1859), $B$. rubrovenosum (Stål, 1860), $B$. sanguinosum (Stål, 1872) e $B$. trux (Stål, 1859).

Até o início do século $\mathrm{XX}$, foram descritas: $B$. colossus (Distant, 1902), B. decolor (Walker, 1873), B. pallitarsis (Walker, 1873) e $B$. rufonotatum (Champion, 1899) (Wygodzinsky, 1949 e 1951; Maldonado Capriles, 1990).

Wygodzinsky (1951) descreveu B. infensum Wygodzinsky, 1951, $B$. oglobini Wygodzinsky, 1951, B. oglobini minor Wygodzinsky, 1951 e, ao mesmo tempo considerou $B$. haematodes (Blanchard, 1846) como sinônimo júnior de $B$. discus (Burmeister, 1835).

Carpintero (1980), além de descrever $B$. abbas Carpintero, 1980, $B$. arlequin Carpintero, 1980, B. castaneus Carpintero, 1980, B. cicheroi Carpintero, 1980, B. discus nigricans Carpintero, 1980, B. lilloi Carpintero, 1980, B. mazzai Carpintero, 1980 e B. nanus Carpintero, 1980, considerou B. decolor (Walker, 1873) sinônimo júnior de B. rubrum (A. \& S., 1843). Finalmente, Gil-Santana et al. (2004), descreveram Brontostoma bahiensis Gil-Santana, Costa \& Marques, 2004.

Porém, os últimos autores a tratar de Brontostoma divergem sobre o assunto. Maldonado Capriles (1990) considerou $B$. decolor e $B$. haematodes espécies válidas. Dougherty (1995) omitiu $B$. alboannulatum, $B$. decolor, B. haematodes, $B$. pallitarsis e as subespécies $B$. oglobini minor e B. discus nigricans (Gil-Santana et al., 2004).

Brontostoma só possui representantes na região Neotropical, com a maioria das espécies ocorrendo na América do Sul (Champion, 1899; Wygodzinsky, 1949; Wygodzinsky, 1951; Maldonado Capriles, 1990; Dougherty, 1995). O maior número de espécies ocorre na Argentina, Brasil e Uruguai (Carpintero \& Maldonado Capriles, 1996).

A análise comparativa das estruturas fálicas tem sido uma grande aliada dos taxonomistas desde que Singh-Pruthi (1925) evidenciou uma constelação de estruturas na genitália dos hemípteros. Desde então, transcorreu um enorme hiato até que aquelas estruturas viessem a ser utilizadas em taxonomia (Jurberg, 2003). Dupuis $(1955,1963)$ organizou a nomenclatura das estruturas, facilitando o entendimento da linguagem utili- 
zada pelos diversos autores. Jurberg et al. (1997) demonstraram a importância da análise comparativa entre as estruturas fálicas como auxiliar na Taxonomia, Sistemática e estudo filogenético dos táxons.

Até o presente, apenas $B$. rubrum havia sido minuciosamente analisado quanto às suas estruturas fálicas, as quais foram relacionadas com espécies pertencentes às subfamílias: Microtominae, Peiratinae, Reduviinae e Triatominae (Jurberg, 1977).

As estruturas genitais masculinas de $B$. doughertyae sp. nov. são comparadas com as de Brontostoma rubrum (Amyot \& Serville, 1843), espécie relativamente comum e de larga distribuição geográfica, registrada para Argentina, Bolívia, Brasil, Guiana, Paraguai, Peru e Suriname (Dougherty, 1995).

\section{Chave para as espécies de Brontostoma do Brasil, baseada em Wygodzinsky (1951) e Gil-Santana et al. (2004)}

1. Cabeça, tórax e esternitos enegrecidos; conexivo com marcações amareladas

1 '. Coloração do tórax, esternitos e conexivode outra forma ................... 3

2. Cório dos hemiélitros branco amarelado geralmente com duas manchas róseo-avermelhadas, uma na base e a outra no ápice. Conexivo amarelado, com a borda interna dorsal enegrecida ................ B. doughertyae sp. nov. 2.' Cório dos hemiélitros negro, com faixas amareladas ao longo das nervuras principais do cório. Conexivo com a metade basal de cada segmento amarelada e a distal enegrecida B. bahiensis

3. Lobo anterior do pronoto uniformemente escurecido a enegrecido ...... 4 3'. Lobo anterior do pronoto total ou parcialmente avermelhado ............... 6

4. Lobo posterior do pronoto inteiramente avermelhado. Cório avermelhado com uma mancha escura longitudinal central ........................... infensum 4'. Lobo posterior do pronoto com mais de uma cor. Cório negro ou bem escurecido

5. Cório enegrecido, com manchas vermelhas: a maior na base e duas menores junto à membrana. Região pleural do tórax com cinco man- 
chas vermelhas que podem mostrar-se variavelmente fundidas entre si fraternum

5'. Cório negro a bem escurecido, com 2 a 4 faixas longitudinais vermeIhas, que podem ou não vir acompanhadas por faixas transversais entre as mesmas. Região pleural avermelhada ou escurecida colossus

6. Cório amarelo ou vermelho, sem marcações 7

6'.Cório negro, com marcações vermelhas ou amarelas de extensão variada 8

7. Espaço interocular do macho medindo até uma vez e meia a largura do olho; o da fêmea até duas vezes esse valor. Segmentos basais da antena do macho com pêlos longos oglobini 7'. Espaço interocular do macho medindo duas vezes a largura do olho; o da fêmea mais que duas vezes esse valor. Segmentos basais da antena do macho sem pêlos. rubrum

8. Pronoto vermelho, o lobo posterior geralmente apresenta uma grande mancha central enegrecida, que pode estar dividida em duas menores ou estar ausente. Cório negro com uma faixa longitudinal estreita, às vezes quase imperceptível discus 8'. Sem essa combinação de caracteres 9

9. Pronoto vermelho ou avermelhado, sem manchas. Hemiélitros negros, com a sua base avermelhada circumductum 9'. Pronoto vermelho ou mais escurecido, podendo ter manchas ou faixas escurecidas. Hemiélitros escurecidos com marcações avermelhadas ao longo do cório

10. Fêmures medianos muito espessados, possuindo uma conspícua saliência ventral submediana ................................................. colossus 10 '. Fêmures medianos pouco espessados, sem saliência ventral 11

11. Conexivo escuro, com o bordo externo amarelo alboannulatum

11'. Conexivo com manchas claras e escuras alternadas rubrovenosum 


\section{Brontostoma doughertyae sp. nov. Descrição do macho (Figs. 2 - 17)}

Dimensões (em mm) - Corpo: comprimento: 21,0 - 24,0. Cabeça: comprimento: 3,2 - 3,5; largura total (incluindo os olhos): 2,9 - 3,1; largura entre os olhos: 1,2 - 1,3; antena: segmento I: 2,5 - 2,8; segmento II: 3,0 3,3; segmento III: 1,8 - 1,9; segmento IV: 0,9 - 1,0; segmento V: 0,9 - 1,0; segmento $\mathrm{VI}: 0,4$ - 0,5; segmento $\mathrm{VII}: 0,6$ - 0,8; comprimento total do rostro: 3,7 - 4,1; segmento I: 1,9-2,1; segmento II: 1,0 - 1,2; segmento III: 0,6 - 0,8. Tórax: lobo anterior do pronoto: comprimento: 1,7 - 1,8; largura: 4,0 - 4,3; lobo posterior do pronoto: comprimento: 2,6 - 3,0; largura: 6,0 - 6,6; comprimento do escutelo: 2,1 - 2,3; largura do escutelo: 2,6 - 2,9; comprimento do hemiélitro: 16,0 - 17,0; pernas anteriores: fêmur: 3,8 - 4,0; tíbia: 4,2 4,7; tarso: 1,6 - 1,8; pernas médias: fêmur: 3,8 - 4,0; tíbia: 4,3 - 4,4; tarso: 1,6 - 1,7; pernas posteriores: fêmur: 6,0 - 6,5; tíbia: 7,0 - 7,1; tarso: 2,1 2,2. Abdome: comprimento: 12,0 - 14,8; largura: 6,8 - 7,9.

Superfície corporal lisa e glabra, com pêlos longos, curtos e finos nas antenas, metade a 2/3 apicais das faces internas das tíbias e nos tarsos.

Cabeça subtriangular, olhos salientes; tubérculo ocelar único e proeminente; rostro cobrindo a extremidade anterior do sulco estridulatório; coloração negra, ligeiramente mais clara nas articulações entre os segmentos do rostro. Antenas com sete segmentos, castanho escura a negra com a metade apical do $3^{\circ}, 4^{\circ}, 5^{\circ}$ e $6^{\circ}$ segmentos amarelos a branco amarelados; no $4^{\circ}$ segmento observa-se, também, um anel escurecido apical. Todos os segmentos antenais têm pêlos finos e longos, mais numerosos nos três primeiros segmentos.

Tórax: negro, com tegumento brilhoso (Fig. 2). Pronoto: sulco transverso bem marcado; no lobo anterior o sulco mediano longitudinal é representado por depressão posterior que não alcança o sulco transverso. No lobo posterior, o mesmo é tênue e limita-se à metade anterior do segmento. Escutelo com duas pontas curtas e pouco convergentes. Sulco estridulatório levemente mais claro na parte anterior. Pernas: coxas, trocânteres e pleuras bem escurecidas, com tegumento brilhoso. Fêmures enegrecidos, os anteriores bem espessados, os médios menos espessados e os posteriores retilíneos com leve entumescimento pré-apical. Nos exemplares provenientes da Bahia observa-se a seguinte variação: fêmures anteriores apresentando um anel amarelado subapical bem nítido em um deles e quase inexistente no outro; os fêmures médios e posteriores são amarelados com 
manchas enegrecidas medianas nas faces superiores e inferiores daqueles e na inferior destes, muito tênues em dos espécimes; nota-se, ainda, estreita faixa escurecida apical em ambos. Tíbias anteriores e médias com fossas esponjosas ocupando mais de $1 / 3$ do ápice naquelas e pouco menos de 1/3 destas últimas, apresentando-se bastante entumescidas na região das fossas esponjosas; nas posteriores há somente um tufo de pêlos dourados no ápice. Tíbias amareladas, com pêlos dourados na face interna e em torno das fossas esponjosas citadas; todas possuem curto anel escurecido basal e outro apical de comprimento variável, ocupando a metade distal no par anterior, o quarto distal no médio e o extremo apical no posterior. Tarsos trímeros; segmentos I e II de todas as pernas amarelados a amarelo-escurecidos; segmentos III castanho-escuros; unhas com a metade apical escurecida. Hemiélitros: cório branco amarelado com duas manchas róseo-avermelhadas: uma na base, externa à sutura claval e a outra no ápice, junto às extremidades das nervuras Sc e R (Fig. 2); nos exemplares provenientes da Bahia, só observam-se as manchas apicais, ausentes as da base. O ápice externo do cório é enegrecido, em continuidade com a membrana que tem a mesma coloração. Nesta última, a porção basal das nervuras, em extensão variável, é levemente amarelada, característica mais evidente e em maior extensão na nervura Cubital $(\mathrm{Cu})$.

Abdome: negro; conexivo amarelado, com a borda interna dorsal enegrecida (Fig. 2). Esternitos negros possuindo tegumento liso com ligeiras rugosidades nas faces laterais, variáveis entre os indivíduos examinados. Um dos parátipos apresenta uma pequena mácula clara na porção apical mediana do $5^{\circ}$ esternito, que continua no terço basal mediano do $6^{\circ}$. Espiráculos elípticos. Cápsula genital enegrecida.

Genitália do macho de $B$. doughertyae sp. nov. (Figs. 3 - 10) é formada pelo $8^{\circ}$ e $9^{\circ}$ segmentos abdominais, este também denominado Pigóforo (IX). O Oitavo segmento é representado pelo $8^{\circ}$ esternito (8st) que se constitui uma placa trapezoidal, dobrada nos bordos laterais, apresentando uma depressão na base do trapézio e estrangulamento no ápice, enquanto que o oitavo tergito (8t) é constituído por uma faixa membranosa. O Pigóforo (IX), designado por alguns autores como câmara genital devido ao seu aspecto capsular, é ovóide, sendo representado em sua totalidade pelo nono esternito (9st). O seu terço apical apresenta redução na sua conformação, fato que permite o encaixe do $8^{\circ}$ segmento. $O$ nono tergito (9t) é representado por uma área membranosa semicircular. $\mathrm{O}$ pigóforo possui duas aberturas: a basal que se encontra ligada ao $8^{\circ}$ segmento por meio de uma membrana 


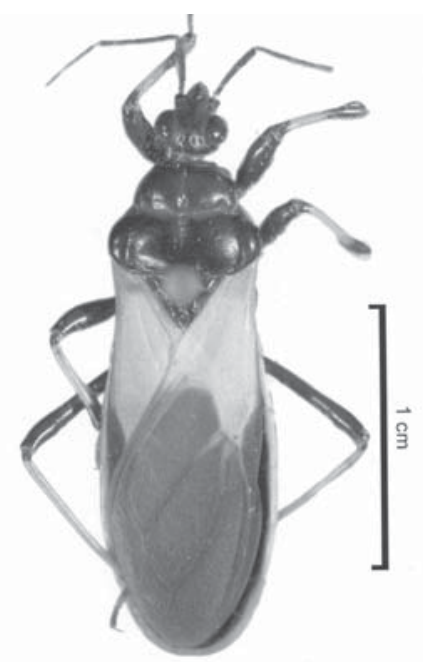

Figura 2: Brontostoma doughertyae sp. nov., macho holótipo, vista dorsal.

elástica que permite a projeção dos segmentos da genitália no ato da cópula e a abertura apical por onde se everte o falo $(\mathrm{P})$, este último apresenta-se rodeado de 05 (cinco) estruturas, a saber : 1 - o processo mediano do Pigóforo (PrP), estrutura ímpar, bastante quitinizada, localizado no bordo basal da abertura, com uma projeção triangular, de ápice arredondado, com numerosas cerdas longas; 2 - os parâmeros ( $\mathrm{Pa}$ ), constituídos por $1+1$ estruturas cilíndricas, curvadas com um pequeno dente esclerotizado no ápice e com cerdas no bordo interno e na porção apical; 3 - os Processos Superiores do Pigóforo (PrSP), constituídos por 1+1 estruturas formadas por pequenas placas, pouco quitinizadas que ladeiam a abertura genital e que têm a função de cerrar ou abrir a abertura genital; 4 - o décimo segmento $(X)$, o qual encontra-se ligado ao $9^{\circ}$ tergito, sendo constituído por um tubo membranoso, recoberto de finos pêlos na extremidade da face dorsal. Neste está telescopado o $11^{\circ}$ segmento que representa o ânus (A); 5 - o falo (P), que se encontra alojado no interior do Pigóforo e é composto de duas partes: o aparelho Articular (Apb) e o Edeago (Ae). O Aparelho articular (Apb) funciona como estrutura móvel que projeta o edeago para fora do corpo do macho e é constituído por uma placa basal (Plb), tubuliforme, cujo aspecto assemeIha-se à letra $Y$ invertida quando das posições dorsal ou ventral. A extensão mediana da placa basal (EPlb), de contorno trapezoidal, pouco quitinizada, liga externamente a placa basal (Plb) ao edeago $(\mathrm{Ae})$ e o processo do 
gonopóro (PrG), este último com aspecto ovóide, serve como condutor do ducto ejaculatório (Dej). Na sua porção distal encontra-se soldada a vesícula seminal (Vs) (em forma de taça) e na região proximal ao edeago e ao suporte do falosoma (SPh). O edeago (Ae), de formato globoso, é constituído de várias estruturas: 1 - uma membrana externa denominada conjuntiva $(\mathrm{Cj})$, que envolve superiormente o órgão; 2 - uma placa inferior, bastante quitinizada denominada de falosoma ( $\mathrm{Ph}$ ), que atinge 2/3 do comprimento do edeago, com bordos laterais arredondados, tendo no ápice, um depressão. Dentro do edeago localiza-se o endosoma (En) membranoso, elástico, com uma estrutura mais quitinizada, ímpar, implantada no ápice, que é a Vesica (V), tendo ainda o processo do endosoma (PrEn). No assoalho do edeago está localizado o suporte do falosoma (Sph), cilíndrico, oco, que ocupa 2/3 do comprimento do edeago.

Distribuição geográfica: BRASIL, Sul do Estado da Bahia (Município de Barro Preto - 14 43' 10" S; 39²2' 05" W) e Norte do Estado do Espírito Santo (Municípios de Linhares e Sooretama -1903' - $19^{\circ} 23^{\prime}$ S; $39^{\circ}$ $\left.52^{\prime}-40^{\circ} 04^{\prime} \mathrm{W}\right)$.

Etimologia: A espécie foi dedicada à Dra. Veronica Dougherty, pela sua contribuição ao estudo dos Ectrichodiinae.

Material Tipo: Brontostoma doughertyaesp. nov.: Holótipo: 10', VIII.1992, BRASIL, Espírito Santo, Linhares (19² $\left.23^{\prime} \mathrm{S}-40^{\circ} 04^{\prime} \mathrm{W}\right)$, Reserva Florestal da Companhia Vale do Rio Doce (RFCVRD), depositado na coleção entomológica do Museu Nacional da Universidade Federal do Rio de Janeiro (MNRJ). Parátipos: BRASIL, Bahia, Barro Preto (14 43' 10" S; 39 22' 05" W), 10', Parátipo, XI.2003, depositado no Museu Entomológico da Escola de Agronomia da Universidade Federal da Bahia, Oton M. Marques col., 10", Parátipo, 26.II.2003, Oton M. Marques col.; Espírito Santo, Linhares (19² 23' S - 40 04' W), Reserva Florestal da Companhia Vale do Rio Doce (RFCVRD): 2đ, Parátipos, 31.X.1992, 26.Il.1993, José Simplício dos Santos col., depositados na coleção entomológica do Museu Nacional da Universidade Federal do Rio de Janeiro (MNRJ); Parque Sooretama (atualmente

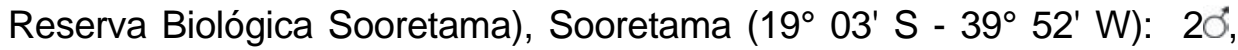
Parátipos, II/III. 1948, H. Travassos, Freitas \& L. Travassos col., depositados na Coleção Entomológica [Geral] do Instituto Oswaldo Cruz (IOC), 10', Parátipo, 19??, D. Zajciw col. (MNRJ). 

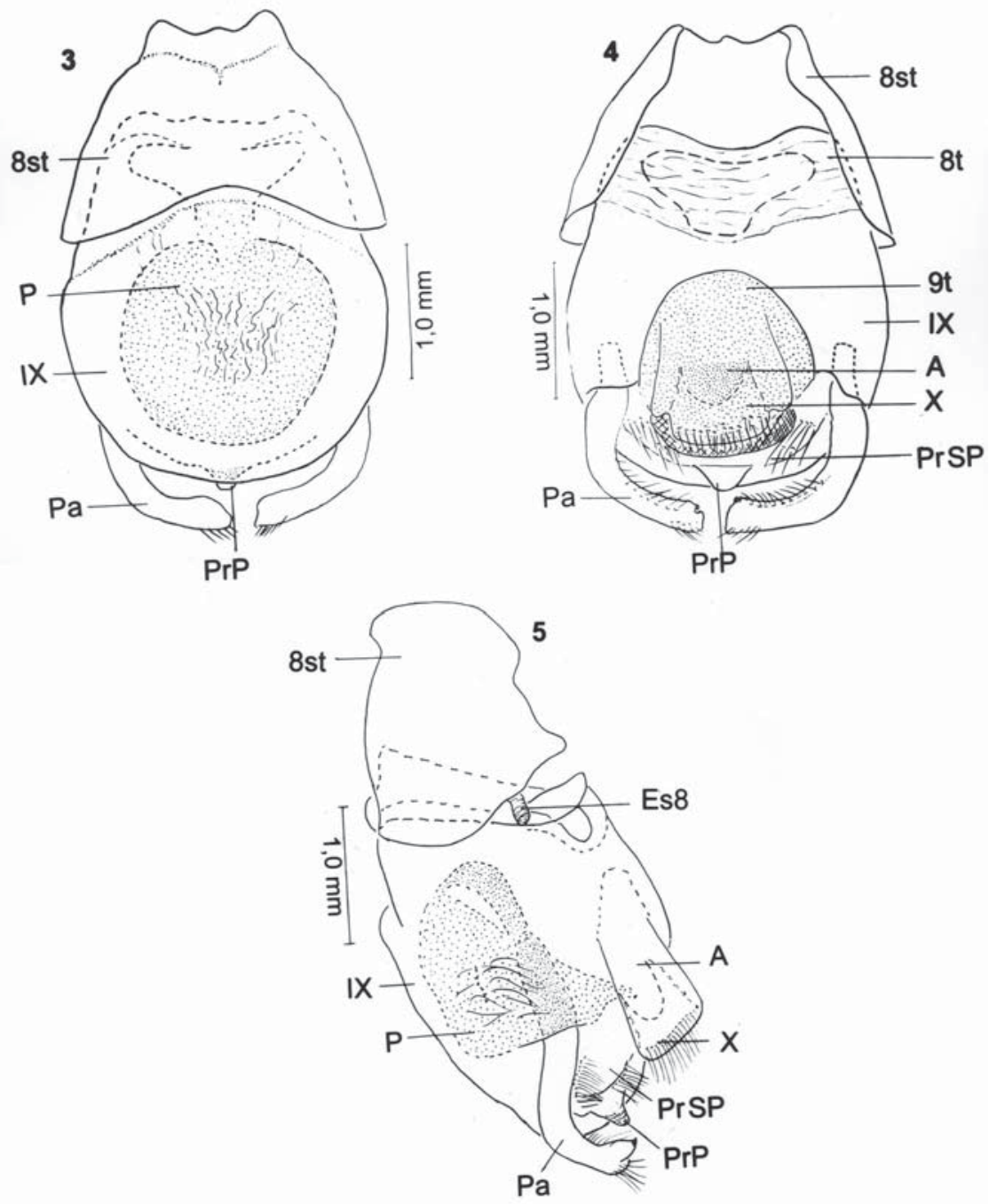

Brontostoma doughertyae sp. nov., genitália do macho: Fig. 3: falo, vista dorsal; Fig. 4: falo, vista ventral; Fig. 5: falo, vista lateral, A - Ânus; 8st Oitavo esternito; 8t - Oitavo tergito; 9 st: Nono esternito; $9 t$ - Nono tergito; IX: Pigóforo; P - falo; Pa - Parâmeros; PrP - Processo mediano do Pigóforo; PrSP - Processo superior do Pigóforo. 

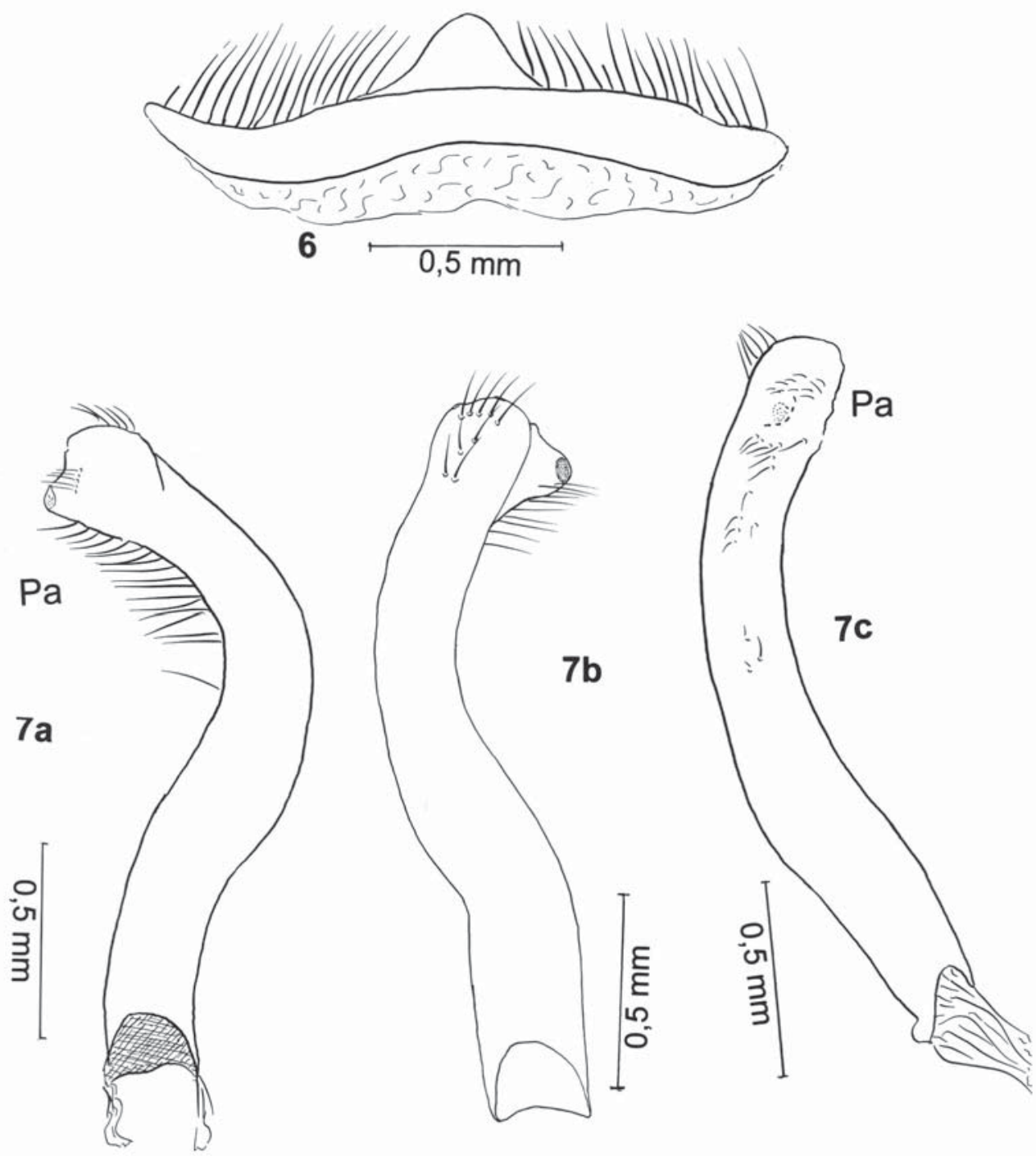

Brontostoma doughertyae sp. nov., genitália do macho: Fig. 6: Detalhe do Processo Superior do Pigóforo (PrSP) . Fig. 7a: Parâmero (Pa), vista lateral; Fig. 7b: Idem, vista dorsal; Fig. 7c: Idem, vista ventral. 

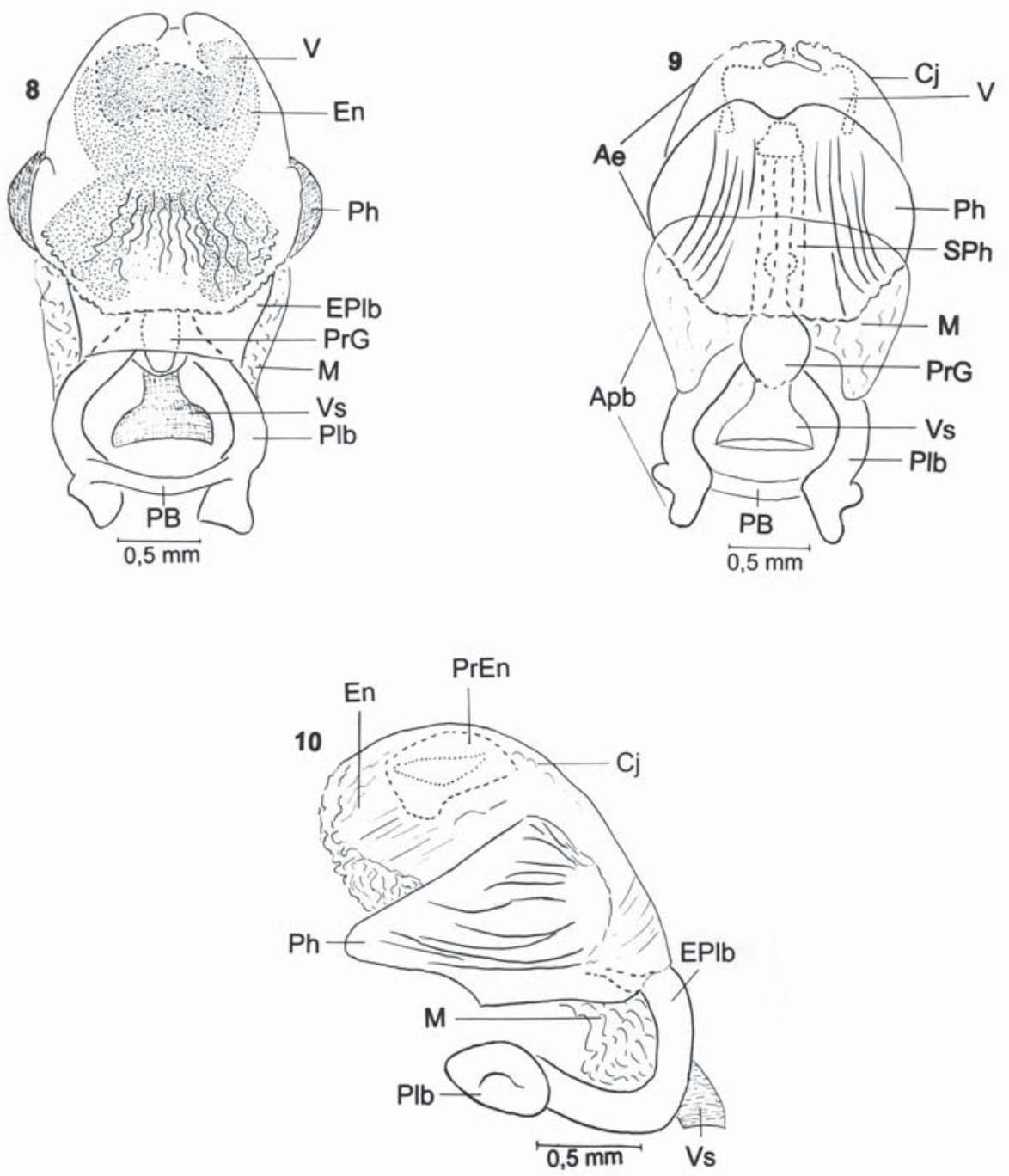

Brontostoma doughertyae sp. nov., genitália do macho: Fig. 8: falo, vista dorsal; Fig. 9: falo, vista ventral; Fig.10: falo, vista lateral, Ae - Edeago; Apb - Aparelho Articular; Cj - Conjuntiva; En - Endosoma; Eplb - Extensão mediana da placa basal; PB - Ponte basal; PIb - Placa basal; PrEn - Processo do Endosoma; PrG - Processo do Gonoporo. PrPh - Processo do falosoma; Ph falosoma; SPh - Suporte do falosoma; Vésica; Vs - Vesícula Seminal. 


\section{Discussão}

Brontostoma doughertyae sp. nov. difere das demais espécies conhecidas do gênero pela coloração do tórax, inteiramente negro e dos hemiélitros, que possuem o cório branco-amarelado com pequenas máculas róseas.

A análise do falo das duas espécies estudadas mostrou a complexidade de seis estruturas: Processo mediano do Pigóforo (PrP); falosoma $(\mathrm{Ph})$; suporte do falosoma (SPh); processo do gonoporo (PrG); parâmeros (Pa) e Processo do Endosoma (PrEn).

As diferenças marcantes entre as estruturas fálicas de $B$. doughertyae sp. nov. e as de B. rubrum estãona Tabela I e Figuras 11 a 17.

Brontostoma doughertyae sp. nov. possui grande semelhança de coloração com outro reduviídeo da região amazônica: Microtomus cinctipes (Drury, 1782) (Hammacerinae), o qual apresenta o corpo, as pernas e membrana do hemiélitros escurecidos e o cório destes últimos, branco a ligeiramente amarelado. Esse aspecto geral de coloração escurecida do corpo com a região central do cório inteiramente clara (de branca a amarelada) é encontrado, também, em Apiomerini (Harpactorinae) da Região Amazônica, como p. ex., a variedade discopterus de Apiomerus nitidicollis Stål, 1872 e Calliclopius nigripes (Linnaeus, 1758) (Gil-Santana et al., 2003) e outras espécies de Apiomerus dessa região. A espécie de Hammacerinae simpátrica à $B$. doughertyae sp. nov., Microtomus conspicillaris (Drury, 1782) (GilSantana \& Alencar, 2001), difere desse padrão por possuir quase sempre uma mácula escura central mais ou menos extensa no cório (Costa Lima, 1935). Assim, é possível que a coloração geral de $B$. doughertyae sp. nov. tenha se desenvolvido por modelo aposemático de ocorrência em reduviídeos amazônicos, corroborando outras observações de semelhança entre a fauna da região de Linhares e Sooretama (ES) com a da Amazônia. Nesse mesmo sentido, entre os Reduviidae, registrou-se a presença de Beharus cylindripes (Fabricius, 1803) (Harpactorinae: Apiomerini), espécie de larga distribuição na região amazônica (GilSantana et al., 2003), na Reserva de Linhares - ES (Gil-Santana \& Alencar, 2001; Gil-Santana et al., 2001), sem nenhum relato da mesma para outra área de Mata Atlântica. 

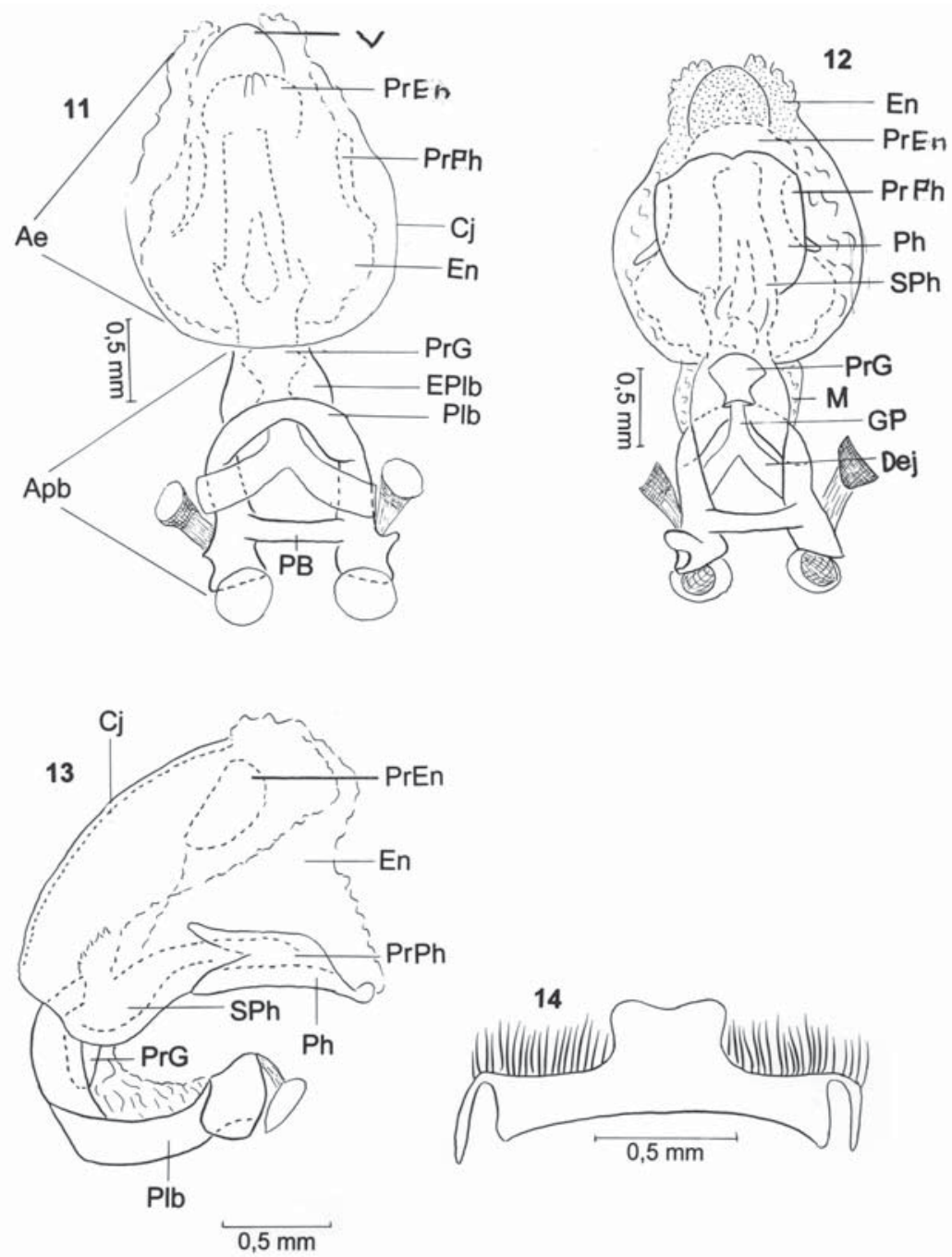

Brontostoma rubrum (Amyot \& Serville, 1843), genitália do macho - Fig. 11: falo, vista dorsal; Fig. 12: falo, vista ventral; Fig. 13: falo, vista lateral; Fig. 14: Detalhe do Processo superior do Pigóforo, Ae - Edeago; Apb - Aparelho Articular; Cj - Conjuntiva; En - Endosoma; Eplb - Extensão mediana da placa basal; PB - Ponte basal; Plb - Placa basal; PrEn - Processo do Endosoma; PrG - Processo do Gonoporo; PrPh - Processo do falosoma; Ph - falosoma; SPh - Suporte do falosoma (Jurberg, 1977 - redesenhado). 
15

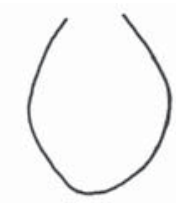

doughertyae

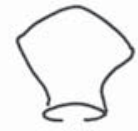

rubrum

$\overline{0,5 \mathrm{~mm}}$

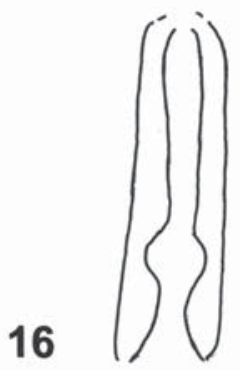

doughertyae

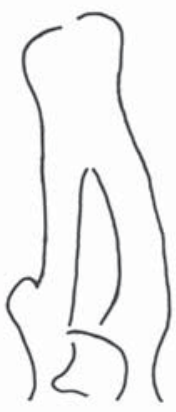

rubrum

Brontostoma doughertyae sp. nov. e Brontostoma rubrum (Amyot \& Serville, 1843): Fig. 15: Processo do Gonoporo (PrG); Fig. 16: Suporte do falosoma (SPh).

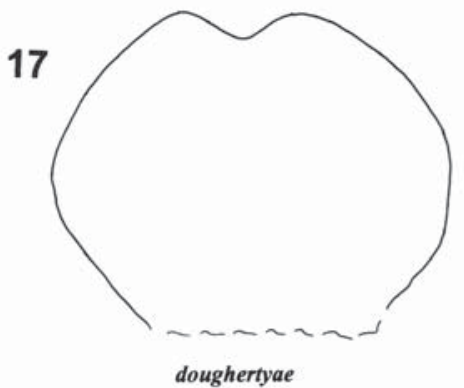

$\overline{0.5 \mathrm{~mm}}$

Figura 17: Falosoma (Ph) de Brontostoma doughertyae sp. nov. e Brontostoma rubrum (Amyot \& Serville, 1843). 
Tabela I

Diferenças entre as estruturas fálicas de $B$. doughertyae sp. nov.

e B. rubrum (Amyot \& Serville, 1843)

(B. rubrum, redesenhado de Jurberg, 1977)

\begin{tabular}{l|l|l}
\hline $\begin{array}{l}\text { Estruturas } \\
\text { fálicas }\end{array}$ & B. doughertyae sp. nov. & B. rubrum \\
\hline $\begin{array}{l}\text { Processos do } \\
\text { Endosoma (PrEn) }\end{array}$ & $\begin{array}{l}\text { Com 1 + 1 projeções } \\
\text { afiladas (Fig. 10). }\end{array}$ & $\begin{array}{l}\text { Com 1 +1 projeções } \\
\text { arredondadas (Fig. 13). }\end{array}$ \\
\hline $\begin{array}{l}\text { Falosoma (Ph) } \\
\text { Maior; arredondado; parte } \\
\text { superior deprimida (Figs. 9 } \\
\text { e 17). }\end{array}$ & $\begin{array}{l}\text { Menor; quadrangular; parte } \\
\text { superior deprimida, com 1 + 1 } \\
\text { processos laterais (Fgis. 12 e 17). }\end{array}$ \\
$\begin{array}{l}\text { Suporte do } \\
\text { falosoma (SPh) }\end{array}$ & $\begin{array}{l}1+1 \text { braços laterais } \\
\text { paralelos com bordos } \\
\text { base (Figs. 9 e 16). }\end{array}$ & $\begin{array}{l}1+1 \text { braços laterais soldados } \\
\text { no ápice e na base, com uma } \\
\text { projeção (Figs. 12 e 16). }\end{array}$ \\
\hline $\begin{array}{l}\text { Processo do } \\
\text { gonoporo (PrG) }\end{array}$ & Oval (Figs. 9 e 15). & Pentagonal (Figs. 12 e 16). \\
\hline $\begin{array}{l}\text { Processo } \\
\text { mediano do } \\
\text { Pigóforo (PrP) }\end{array}$ & $\begin{array}{l}\text { Ápice triangular } \\
\text { (Figs. 5 e 6). }\end{array}$ & Ápice bifurcado (Fig. 14). \\
\hline
\end{tabular}

\section{Agradecimentos}

Ao Gerente Geral da RFCVRD de Linhares, Sr. Renato Moraes de Jesus pela cessão dos exemplares provenientes daquela localidade; Sr. José Simplício dos Santos, funcionário da RFCVRD, pelo auxílio prático no acesso ao material dessa Instituição; Prof. Dr. P. H. van Doesburg Jr. (Rijksmuseum van Natuurlijke Historie, Leiden - Holanda), pelo auxílio na obtenção dos trabalhos de Carl Stål; Sr. Luiz A. A Costa (Museu Nacional da Universidade Federal do Rio de Janeiro - MNRJ), pelo auxílio na localização e estudo do parátipo de $B$. doughertyae sp. nov. dessa Coleção; Biólogo e Heteropterista Dimitri Forero (Cornell University - EUA), pelas sugestões apresentadas e colaboração na 
obtenção de referências bibliográficas; ao saudoso Prof. Johann Becker (MNRJ), pelo empréstimo do livro de Amyot \& Serville (1843); Almirante Centro de Estudos de Cacau, pelo financiamento da pesquisa que permitiu a coleta dos exemplares de Brontostoma doughertyae sp. nov., provenientes do Estado da Bahia.

\section{Referências Bibliográficas}

Amyot, C.J.B. \& Serville, A., 1843. Histoire Naturelle des Insectes. Hémiptères. Paris, Libraire Encyclopedique de Roret, Fain et Thunot, $675 \mathrm{p}$.

Carpintero, D.J., 1980. Nuevos Ectrichodiinae Americanos (Insecta Hemiptera - Reduviidae). Acta Scient. Entom. 14 3-33.

Carpintero, D.J. \& Maldonado Capriles, J., 1996. Diagnostic characters and key to the Genera of American Ectrichodiinae (Heteroptera, Reduviidae). Carib. J. Sci. 32:125-141.

Costa Lima, A. da., 1935. Gênero Microtomus Illiger, 1807. Ann. Acad. Bras. Ciencias 7:315-323.

Champion, G.C., 1899. Insecta Rhynchota. Hemiptera-Heteroptera, Vol II: 229-243. In: Biologia Centrali Americana. Rhynchota (Godwin \& Salvin, eds.) London, $416 \mathrm{p}$.

Coscarón, M.C.; Loiácono, M.S. \& De Santis, L., 1999. Predators and parasitoids. Predadores e parasitóides. Volume 3: 891-924. In: Atlas dos Vetores da Doença de Chagas nas Américas (R.U. Carcavallo, I. Galindez Girón, J. Jurberg \& H. Lent eds). Editora Fiocruz, Rio de Janeiro. 1217 p.

Dougherty, V., 1995. A review of the New World Ectrichodiinae Genera (Hemiptera: Reduviidae). Trans. Amer. Entomol. Soc. 121:173-225.

Dupuis, C., 1955. Les genitalia des Hemiptères Hétéroptères. Mem. Mus. Nat. Hist. Natur. Serie A, Zool. N. S. 6:183-278. 
Dupuis, C., 1963. Progrès récent de l'etude des genitalia des Hétéroptères (Etude bibliographique critique). Thèse à Faculte des Sciences de l'Université, Paris, 100 p. Mus. Nat. Hist. Natur. Paris Ed. Paris.

Gil-Santana, H.R. \& Alencar, J., 2001. Reduviidae da Reserva Florestal de Linhares, Espírito Santo, Brasil (Hemiptera-Heteroptera). Rev. Bras. Zoociências 3:171-176.

Gil-Santana, H.R.; Alencar, J. \& Jurberg, J., 2001. Redescrição de Beharus cylindripes (Fabricius, 1803), com o primeiro registro de sua ocorrência no Brasil (Hemiptera, Reduviidae, Apiomerinae). Entomol. Vect. 8:185-192.

Gil-Santana, H.R.; Costa, L. A.A.; Forero, D. \& Zeraik, S.O., 2003. Sinopse dos Apiomerini, com chave ilustrada para os gêneros (Hemiptera-Heteroptera, Reduviidae, Harpactorinae). Publ. Avulsos Mus. Nac. 97:1-12.

Gil-Santana, H.R.; Costa, L. A. A. \& Marques, O.M., 2004. Brontostoma bahiensis sp. nov. de Ectrichodiinae (Hemiptera, Heteroptera, Reduviidae) do Estado da Bahia, Brasil. Rev. Bras. Zool. 21:127-130.

IBAMA., 2003. Reserva Biológica de Sooretama/ES. 1-3. Disponível em: $<$ http://www2.ibama.gov.br/unidades/biolog/reuc/2010.htm>. Acesso em: 29 junho de 2003.

Jurberg, J., 1977. Contribuição ao estudo da genitália externa em subfamilias de Reduviidae (Hemíptera-Heteroptera). Tese Mestrado, 72 p., Museu Nacional da Universidade Federal do Rio de Janeiro. Rio de Janeiro.

Jurberg, J., 2003. Ferramentas usadas em taxonomia de triatomíneos - 0 uso múltiplo. Entomol. Vect. 10:497-509.

Jurberg, J.; Lent, H. \& Galvão, C., 1997. The male genitalia and its importance in taxonomy. Genitália dos machos e sua importância na taxonomia. Vol. 1: 85-106, In: Atlas dos Vetores da Doença de Chagas nas Américas (R.U. Carcavallo, I. Galindez Girón, J. Jurberg \& H. Lent eds). Editora Fiocruz, Rio de Janeiro, 393p. 
Maldonado Capriles, J., 1990. Systematic Catalogue of the Reduviidae of the World (Insecta: Heteroptera). Caribbean J. Sci., (special ed.), Mayagüez, $694 \mathrm{p}$.

Singh-Pruthi, H., 1925. The morphology of the male genitalia in Rhynchota. Trans. Entomol. Soc. London 1:127-267.

Stål, C., 1859. Till kännedomen om Reduvini. Oefv. K. Vet.- Ak. Foerh. 16:175-204.

Stål, C., 1860. Bidrag till Rio de Janeiro-traktens Hemipter-fauna. I. K. Vet.Ak. Handl. 2:1-84.

Stål, C., 1872. Enumeratio Hemipterorum. K. Sv. Vet.- Ak. Handl. 10:66-123.

Tyler, H.A.; Brown Jr., K.S. \& Wilson, K.H., 1994. Swallowtail Butterflies of the Americas - A Study in Biological Dynamics, Ecological Diversity, Biosystematics and Conservation. Scientific Publishers Inc., Gainesville. 378 p.

Wygodzinsky, P., 1949. Elenco sistematico de los reduviiformes americanos. Inst. Med. Reg. Tucumán 1:1-102.

Wygodzinsky, P., 1951. Notas sobre Ectrichodiinae Neotropicales (Hemiptera, Reduviidae). Rev. Soc. Entomol. Arg. 15:35-52. 